\title{
Hydraulic Characteristics of Tuff (Scoria) used as a Container Medium
}

\author{
R. Wallach, F.F. da Silva, and Y. Chen \\ The Seagram Center for Soil and Water Sciences, Faculty of Agriculture, The Hebrew University of \\ Jerusalem, P. O. Box 12, Rehovoth 76100, Israel
}

Additional index words. volcanic ash, quartz sand, modeling

\begin{abstract}
For effective management of irrigation and fertilization, a complete understanding of the hydraulic properties of container media is essential. This study was conducted to test the applicability of an existing predictive model for calculating the unsaturated hydraulic conductivity $K(h)$ of tuff (Scoria, granulated volcanic ash). Two texturally different types of tuff as well as five fractions $(0-1,1-2,2-4,4-8$, and $>8 \mathrm{~mm})$, obtained from the natural material by sieving, were investigated. A 0 - to 1-mm fraction of quartz sand was also tested and compared to the corresponding fraction of tuff. Water retention curves $0(h)$ (main drying and primary wetting scanning curves) of the media were measured over a 0 - to $120-\mathrm{cm}$ suction range, which covers the range of horticultural interest. The saturated hydraulic conductivity $K_{s}$ was measured after the determination of the range of validity of Darcy's law. The model parameters were determined by curve-fitting of the measured retention data, and the $K(h)$ relationship was obtained by multiplying the calculated relative hydraulic conductivity curve $K$,(h). The model prediction of $K(h)$ was validated following direct and indirect approaches. The results showed that a reliable prediction of the unsaturated hydraulic conductivity of coarsely textured container media consisting of tuff is possible using a model commonly used for regular soils.
\end{abstract}

Tuff is a granulated volcanic material that formed as a result of violent eruptions and rapid cooling of ejected magma containing water vapor and other gases. The use of tuff as a container medium in greenhouse horticulture, as a soil substitute for ornamental in open fields, and as a soil bedding for turf in open sport fields has recently increased in countries that have resources of volcanic ash. Luque (1981) and Unver et al. (1983) reported the use of tuff as a container medium in the Canary Islands and Turkey, respectively. Tuff is also widely used as a container medium for vegetable crops in the southern regions of Italy and France. In Israel, where tuff usage is prevalent and demand for it increases continuously, various types of tuff materials can be found in the country's northern region. Among these is "red" tuff, which owes its designation to its characteristic color. A variety of tuff materials can be found in many countries in the world and, therefore, an expansion of its use is expected.

For effective management of irrigation and fertilization in container media, a complete understanding of their hydraulic properties is essential. The determination of the water retention curve $\theta(\mathrm{h})$ and the hydraulic conductivity as a function of water suction $\mathrm{K}(\mathrm{h})$ is required to solve the transport equations of water and chemicals. Although $\theta(\mathrm{h})$ is relatively easy to determine, many technical difficulties are involved in the measurement of $\mathrm{K}(\mathrm{h})$, mainly because the values of the hydraulic conductivity may vary by several orders of magnitude within the relevant range of water suction (Mualem, 1986). In addition, the measurements are tedious, and common measuring systems cannot efficiently cover wide ranges of variation (Klute and Dirksen, 1986). These impediments probably explain why, to date, the hydraulic characterization of tuff for irrigation management, as well as that of other container media, has been almost exclusively based on $\theta(\mathrm{h})$. In some cases, the saturated hydraulic conductivity of the medium $\mathrm{K}_{\mathrm{s}}$ was also determined (Chen et

Received for publication 9 Aug. 1991. Accepted for publication 4 Feb. 1992. We thank the Israel Vegetable Growers Assn. and the Israel Ministry of Agriculture, Vegetable Growing Branch, for their financial support. The cost of publishing this paper was defrayed in part by the payment of page charges. Under postal regulations, this paper therefore must be hereby marked advertisement solely to indicate this fact. al., 1980; Galin and Singer, 1988). Fonteno et al. (1981), Fonteno and Bilderback (1983), and Karlovich and Fonteno (1986) applied regression analysis to describe the $\theta(\mathrm{h})$ curves of container media used in horticulture. Milks et al. (1989) used the curve-fitting equation proposed by van Genuchten (1980) to describe retention data collected for five porous materials commonly used as container media. This equation has proven to be an excellent tool for fitting the water content vs. water suction relationships for a variety of natural soils, as well as for container media varying widely in their physical properties (Milks et al., 1989).

Retention curves of container media, such as peat and composted wastes, vermiculite, perlite, or rockwool, are characterized by very high water contents at saturation $\theta_{s}$, which decline steeply as suction increases. As a consequence, the $\mathrm{K}_{\mathrm{s}}$ of such media is usually extremely high (Chen et al., 1980; Galin and Singer, 1988). Despite its utmost importance, the unsaturated hydraulic conductivity remains to be determined for substrates used as container media, such as tuff.

Although the use of models to characterize the $\mathrm{K}(\mathrm{h})$ relationship of soils has become popular, it appears that such models have not yet been applied to container media. Many methods have been developed to estimate $K(\mathrm{~h})$ from the $\theta(\mathrm{h})$ curve; van Genuchten (1980) proposed a closed-form analytical solution to the predictive model for $\mathrm{K}(\mathrm{h})$ that was first proposed by Mualem (1976), then modified as follows. The volumetric water content $\theta$ in a relative form, sometimes called effective saturation $S_{e}$, is expressed as:

$$
\mathrm{S}_{\mathrm{e}}=\left(\theta-\theta_{\mathrm{r}}\right) /\left(\theta_{\mathrm{s}}-\theta_{\mathrm{r}}\right),
$$

where the subscripts $\mathrm{s}$ and $\mathrm{r}$ refer to the saturated and residual values of $\theta$, respectively. The latter is defined as the water content at which the gradient $\mathrm{d} \theta / \mathrm{dh}$ becomes zero (excluding the region near $\theta$, which may also present a zero gradient). Also, $\mathrm{K}$ approaches zero when $\theta$ approaches $\theta_{\mathrm{r}}$. van Genuchten (1980) proposed the following equation to represent the $\theta(\mathrm{h})$ function:

$$
\mathrm{S}_{\mathrm{e}}=\left[1+(\alpha \mathrm{h})^{\mathrm{n}}\right]^{-\mathrm{m}},
$$

where $\mathrm{h}$ is the water suction (expressed here as centimeters of water). In Eq. [2], $\alpha, n$, and $\mathrm{m}$ are parameters that determine 
the shape of the retention curve. These parameters are determined by curve-fitting techniques. According to the model developed by Mualem (1976), the relative hydraulic conductivity $\left(\mathrm{K}_{\mathrm{r}}=\mathrm{K} / \mathrm{K}_{\mathrm{s}}\right.$ can be calculated by the following equation:

$$
\mathrm{K}_{\mathrm{r}}\left(\mathrm{S}_{\mathrm{e}}\right)=\mathrm{S}_{\mathrm{e}}^{1 / 2}\left[\int_{0}^{\mathrm{s}_{\mathrm{e}}} \frac{1}{\mathrm{~h}(\mathrm{x})} \mathrm{dx} / \int_{0}^{1} \frac{1}{\mathrm{~h}(\mathrm{x})} \mathrm{dx}\right]^{2},
$$

where $\mathrm{x}$ is an integration variable. Of the various possibilities for restricted $m-n$ cases, the relation $m=1-1 / n$ was shown to perform better than other cases (van Genuchten and Nielsen, 1985). Solving Eq. [2] for $h=h\left(S_{e}\right)$, substituting the resulting expression into Eq. [3], and assuming the above unique relationship between the parameters $\mathrm{n}$ and $\mathrm{m}$ leads to:

$$
\mathrm{K}_{\mathrm{r}}\left(\mathrm{S}_{\mathrm{c}}\right)=\mathrm{S}_{\mathrm{e}}^{1 / 2}\left[1-\left(1-\mathrm{S}_{\mathrm{e}}^{1 / \mathrm{m}}\right)^{\mathrm{m}}\right]^{2},
$$

where $0<\mathrm{m}<1$. In terms of h, Eq. [4] becomes:

$$
\mathrm{K}_{\mathrm{r}}(\mathrm{h})=\frac{\left\{1-(\alpha \mathrm{h})^{\mathrm{n}-1}\left[1+(\alpha \mathrm{h})^{\mathrm{n}}\right]^{-\mathrm{m}\}^{2}}\right.}{\left[1+(\alpha \mathrm{h})^{\mathrm{n}}\right]^{\mathrm{m} / 2}} .
$$

Multiplying the value of $\mathrm{K}_{\mathrm{s}}$ by Eq. [5] will provide the $\mathrm{K}(\mathrm{h})$ function.

The aim of the present study was to test the applicability of this predictive hydraulic model to the characterization of the hydraulic properties of a granular container medium such as tuff. Besides an accurate description and curve-fitting of both drying and wetting retention curves, the calculation of a reliable unsaturated hydraulic conductivity function is of vital practical importance to the development of an effective management regime of irrigation and fertilization.

\section{Materials and Methods}

Two texturally different types of red tuff from northern Israel were chosen and characterized: 1) RTM, a red tuff consisting of particles ranging in size from 0 to $8 \mathrm{~mm}$ and obtained from a tuff strip mine by sieving of the natural product (often specified as tuff $0-8 / \mathrm{M})$. 2) RTB, a coarser red tuff material consisting of particles in the same size range and obtained by crushing large particles (30 to $50 \mathrm{~mm}$ in diameter), then sieving the crushed material through an $8-\mathrm{mm}$ sieve (tuff $0-8 / \mathrm{B}$ ). Five different fractions of tuff obtained by sieving a RTM sample were also analyzed: $0-1,1-2,2-4,4-8$, and > $8 \mathrm{~mm}$. Except for the 0 - to $1-\mathrm{mm}$ fraction, the fractions were washed with running water to remove fine particles. For each medium, samples were collected from the same batch that was thoroughly mixed beforehand. The tuff material was previously wetted to a water content of $\approx 5 \%$ by volume, which allowed uniform packing of the funnels and columns while minimizing segregation of fine particles. To check the differences between tuff and regular soils, a O- to 1-mm fraction of quartz sand was also tested as a model.

A deaerated $0.005 \mathrm{M} \mathrm{CaSO}_{4}$ solution was used for all experiments, as suggested by Klute and Dirksen (1986). To inhibit the development of microorganisms, $50 \mathrm{mg} \mathrm{HgCl}_{2} /$ liter was added to the deaerated water.

\section{Water retention curves}

The method used to measure the $\theta(\mathrm{h})$ curves at low suction range $(0-120 \mathrm{~cm})$ is a modification of the conventional hanging water-column method described by Klute (1986). Samples of the media were packed to a volume of $500 \mathrm{ml}$ in sintered glass funnels and consolidated by tapping a standard number of times.
The media were very slowly wetted to saturation so that the water level coincided with the top of the sample for more than 24 to $48 \mathrm{~h}$. The water content at the end of the saturation procedure was assumed to be $\theta_{s}$. The main drying curve was then initiated by hanging a water column of different lengths, resulting in suctions at the center of the sample of 3.3, 6.6, 10, $15,20,25,30,40,50,60,80,100$, and $120 \mathrm{~cm}$. Volumes of the outflow water were measured for each increment. At the end of the drying cycle (arbitrarily chosen at $\mathrm{h}=120 \mathrm{~cm}$ ), the funnel containing the medium and residual water was weighed. The funnel was then reconnected to the inflow system, composed of a 500-ml constant-head bottle, and the suction was decreased back to zero, resulting in suctions of $120,80,40$, $30,25,20,15,10,5$, and $0 \mathrm{~cm}$ (primary wetting scanning curve). Inflow volume was recorded for each suction level. Volumetric water content for each value of suction was then determined by back calculation. The $\theta(\mathrm{h})$ curves were determined for three replicates.

The parameters of Eq. [2] were estimated for the arithmeticaverage of each set of three replicates. The measured value of $\theta_{s}$, was used for the fitting of the drying curve, whereas for the wetting curve, a maximum ("saturated") value was used for $\theta$, being the average of the values of $\theta$ at the end of the experiment $\left(\theta_{\mathrm{w}}\right)$.

\section{Saturated hydraulic conductivity}

Saturated hydraulic conductivity values $\mathrm{K}_{\mathrm{s}}$ were determined using a modified constant-head method (Klute and Dirksen, 1986). The media were packed in $20-\mathrm{cm}-$ long columns $(5.1 \mathrm{~cm}$ i.d.) and tightly supported by stainless steel \#40 mesh screens $(0.38$ $\mathrm{mm}$ openings) mounted on $1-\mathrm{cm}$-long plastic rings $(5.1 \mathrm{~cm} \mathrm{o.d.)}$. These rings, one at each end of the column, also created a small compartment full of water, thus ensuring one-dimensional flow (Fig. 1). Outflow water was measured with a precision of \pm 0.01 $\mathrm{ml}$. Measurements were initiated only after the system was allowed to flow for about $1 \mathrm{~h}$ to allow enclosed air to be gradually pushed out of the column. Previous to the determination of the $\mathrm{K}_{\mathrm{s}}$ values, the range of validity of Darcy's law was identified by applying a series of gradients and measuring the resulting flux density. The expected data in this range should result in a linear relationship between the flux density $q$ and the hydraulic head $\mathrm{J}$ (passing through the origin). Above some threshold gradient, a nonlinear relationship between $\mathrm{q}$ and $\mathrm{J}$ is expected,

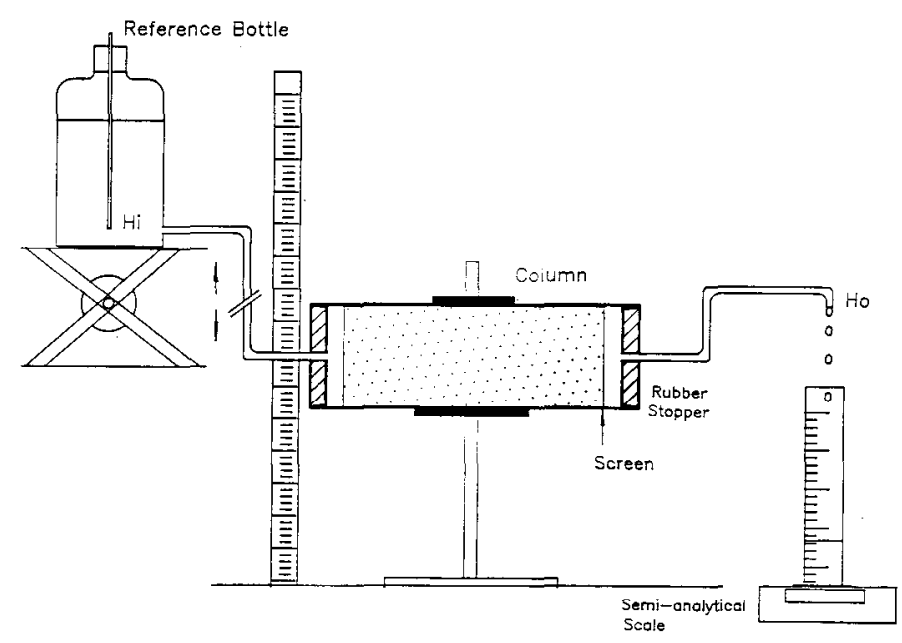

Fig. 1. Experimental setup used for the determination of saturated hydraulic conductivity by the constant-head method. 
Following the identification of the linear relation between a and $\mathrm{J}$, a second experiment was performed on the same sample at a gradient chosen in the middle of the linear range. Four measurements were performed during $2 \mathrm{~h}$ at 30-min intervals. Each experiment was determined in triplicate, and four measurements were made at each level.

\section{Prediction of $\mathbf{K}(\mathbf{h})$}

The value of $\theta_{\mathrm{r}}$ was assumed to be the same for the drying and wetting data and was obtained from the fitted drying branch of the $\theta$ (h) curve, as suggested by van Genuchten $(1978,1980)$. The primary wetting hydraulic conductivity curve was then obtained by multiplying the wetting $\mathrm{K}_{\mathrm{r}}(\mathrm{h})$ relationship by $\mathrm{K}_{w}$, which corresponds to the hydraulic conductivity of the medium at the water content $\theta_{\mathrm{w}}$. This assumption was made because no matching value of $K$ was measured, except for $K_{s}$. The value of $K_{w}$ was determined from the $K(\theta)$ curve, assuming that hysteresis is negligible in the $K(\theta)$ plane, i.e., $K_{w}=K\left(\theta_{w}\right)$.

\section{Measurement of $\mathrm{K}(\mathrm{h})$}

To validate the calculated $\mathrm{K}(\mathrm{h})$ relationship, direct and indirect approaches were followed. The $\mathrm{K}(\mathrm{h})$ curve was directly obtained by using the long-column version $(50 \mathrm{~cm})$ of the steadystate flux control method (Klute and Dirksen, 1986). According to this method, a constant flux of water q is established at the upper end of a vertical, uniformly packed soil column, while its lower end is maintained at atmospheric pressure. A constant $\mathrm{q}$, less than $\mathrm{K}_{\mathrm{s}}$, is applied to the previously saturated column, which drains to a condition of steady-state downward flow. Upon reaching this condition, the suction distribution along the column is expected to be relatively constant throughout its upper region. A unit hydraulic gradient should, therefore, be established in that part of the column, and under these conditions, $\mathrm{K}$ is numerically equal to $\mathrm{q}$.

The experimental setup for this method included a $50-\mathrm{cm}$ long column $(10 \mathrm{~cm}$ i.d. $)$, four tensiometers, a pressure transducer, a manual scanning valve system, and a peristaltic pump (Fig. 2). Each tensiometer consisted of a high-flow ceramic porous cup $(6.30 \mathrm{~cm}$ long, $1.95 \mathrm{~cm}$ o.d., air entry value $>100$ $\mathrm{kPa}$ ), which was mounted horizontally and extended $\approx 6 \mathrm{~cm}$ across the column. The vertical distance between tensiometers was $10.5 \mathrm{~cm}$. Each tensiometer was filled with deionized, deaerated water and the top was sealed with a rubber stopper. A pressure transducer operating in a range of 0 to $100 \mathrm{~cm}$ of water was mounted on a fixed position and connected to the scanning system. The connection between the tensiometer and the transducer was achieved by means of plastic tubing inserted through the rubber stopper. The transducer (constant voltage supply of $12 \mathrm{~V}$ ) was adjusted and calibrated precisely to obtain the relation between voltage and water suction. A multimeter was used to read the resulting voltage output, which is proportional to the suction being sensed.

Starting at saturation, a controlled flow was maintained until the tensiomaer readings were stabilized and the volumetric outflow rate was constant. Due to the unit gradient, the constant flux yielded $\mathrm{K}$, while the suction was measured to obtain the related suction. This process was then repeated at a series of decreasing flow rates, and each time $\mathrm{q}$ and $\mathrm{h}$ were recorded. The experiment was performed in duplicate for RTB and RTM. For each flux, measurements were made until steady state was reached. Achievement of steady-state conditions usually took from several hours to several days.

J. Amer. Soc. Hort. Sci. 117(3):415-421. 1992.

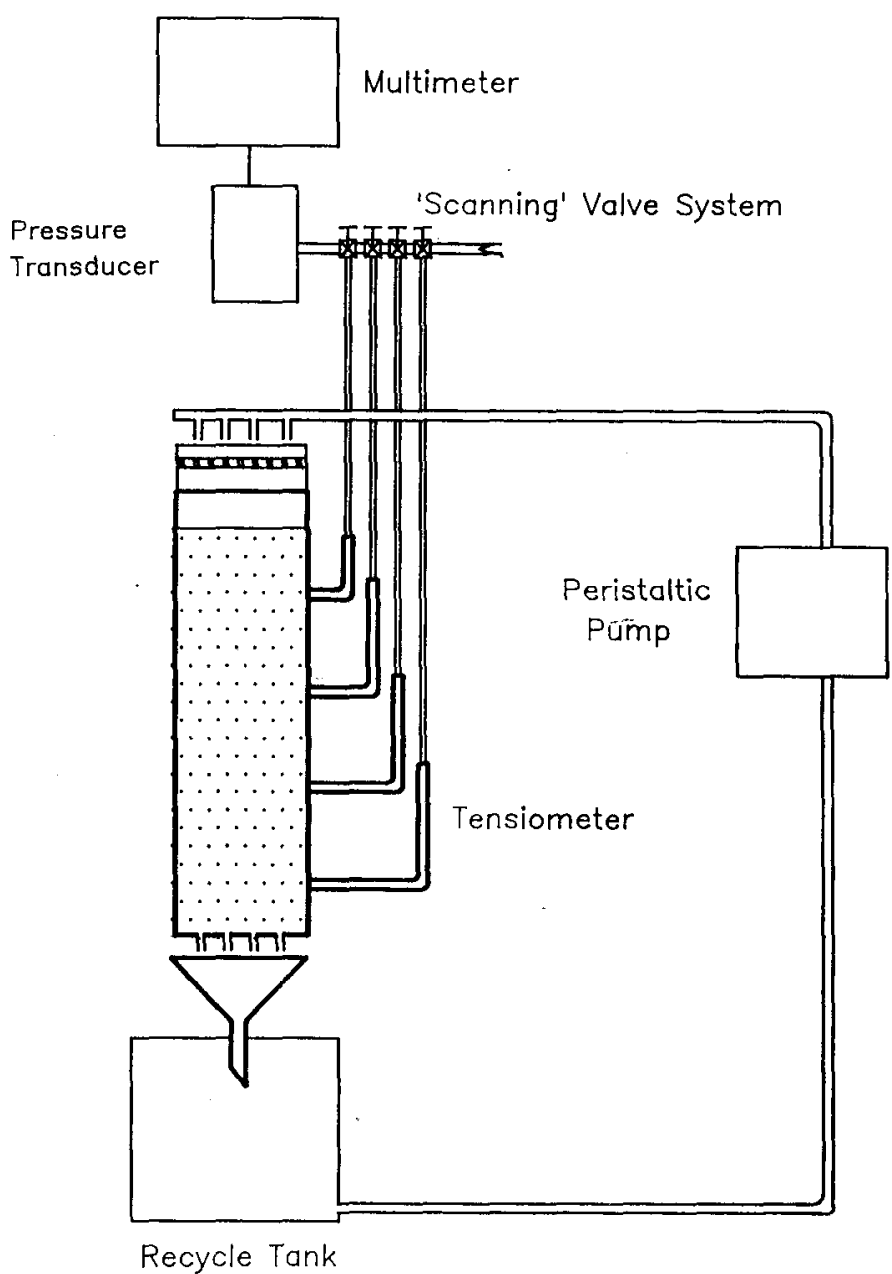

Fig. 2. Experimental setup used for the determination of unsaturated Hydraulic-conductivity by the steady-state flux control method.

For an indirect validation of the calculated $\mathrm{K}(\mathrm{h})$ relationship, the same experimental setup was used. The measured values of $\mathrm{h}$ along the column, for each value of $\mathrm{q}$, were compared with simulated profiles. The $\mathrm{h}(\mathrm{z})$ profiles were simulated by solving the steady-state one-dimensional flow equation:

$$
q=-K(h)\left(\frac{d h}{d z}+1\right)
$$

Rearranging Eq. [6] and integrating between the bottom of the column $(\mathrm{z}=0)$ and its top $(\mathrm{z}=\mathrm{Z})$, gives:

$$
\int_{0}^{z} d x=z=-\int_{0}^{h(z)} \frac{d y}{1+\frac{q}{K(y)}}
$$

where $\mathrm{x}$ and $\mathrm{y}$ are integration variables. Introducing the calculated $\mathrm{K}(\mathrm{h})$ values (drying curve) into Eq. [7] and using a standard numerical integration procedure to solve the equation, the suction was calculated as a function of the column's height.

Variations in the suction profile throughout the unit-gradient region are usually observed, even in the case of "uniformly packed" sand columns (Yeh and Harvey, 1990). Therefore, we used a mean unit-gradient approach, as suggested by Yeh (1989). The average value of suction measured at the tensiometers in the unit-gradient region was assumed to correspond to the mea- 
sured hydraulic conductivity. Since changes in suction occur mainly in the lower and upper ends of the column, only the readings of the two tensiometers located at the center of the column were considered appropriate to represent the unit-gradient region.

\section{Results and Discussion}

The two types of tuff considered in this study differ significantly. RTB contains a higher percentage of coarse particles and has a lower bulk density (Tables 1 and 2). Almost $75 \%$ of the water of saturated RTB was lost within the $0-$ to $25-\mathrm{cm}$ suction range, compared to $\approx 50 \%$ for RTM (Fig. 3). The differences between the two media were evident up to suctions of $50 \mathrm{~cm}$. At higher suctions, however, differences were small; at $\mathrm{h}=120 \mathrm{~cm}, 13$ is only slightly higher for RTM. A higher $\theta$, was registered for RTB than for RTM $\left(0.55\right.$ vs. $0.45 \mathrm{~cm}^{3} \cdot \mathrm{cm}^{-3}$, respectively). This difference results from the higher percentage of coarse fractions in RTB. We believe that clogging of inner pores in large gravel-sized particles of RTM by fine particles also affects $\theta$. The 0 - to $1-\mathrm{mm}$ fraction may account for the higher values of $\theta$ exhibited by RTM for $\mathrm{h}>10 \mathrm{~cm}$ (Fig. 4). This effect of fraction size was also elaborated by testing the f3(h) curves for the 1- to 2-mm and the 2- to 4-mm fractions. The curves for the very coarse fractions $(2-4,4-8$, and $>8 \mathrm{~mm})$ exhibited only minor differences that did not seem to be significant. Therefore, the curves for the 4- to 8-mm and > 8-mm fractions are not presented, and one can consider the curve of the 2- to 4-mm fractions to represent the coarser fractions.

In all cases, $\theta_{\mathrm{s}}$ was much less than total porosity (Tables 2 and 3). Usually $\theta_{s}$ is $\approx 80 \%$ to $90 \%$ of total porosity, due to entrapped air (Klute, 1986). In addition, tuff particles are characterized by occlusive porosity (Chen et al., 1980), which further reduces the effective porosity. This reduction could be seen

Table 1. Particle size distribution of red tuff consisting of very coarse (RTB) and coarse (RTM) material.

\begin{tabular}{lrr}
\hline \hline \multirow{2}{*}{$\begin{array}{l}\text { Particle size } \\
(\mathrm{mm})\end{array}$} & \multicolumn{2}{c}{ Mass fraction $(\%)$} \\
\cline { 2 - 3 } & RTM & RTB \\
\hline $0-1$ & 42.0 & 21.6 \\
$1-2$ & 16.5 & 9.6 \\
$2-4$ & 21.1 & 12.9 \\
$4-8$ & 13.3 & 42.7 \\
$>8$ & 7.1 & 13.2 \\
\hline
\end{tabular}

Table 2. Mean ( $\overline{\mathrm{x}}$ )and standard deviation (SD) values of measured bulk density and calculated porosity for RTM, RTB, and various fractions of the bulk tuff material.

\begin{tabular}{lccc}
\hline \hline & \multicolumn{2}{c}{$\begin{array}{c}\text { Bulk density } \\
\left(\mathrm{g} \cdot \mathrm{cm}^{-3}\right)\end{array}$} & $\begin{array}{c}\text { Porosity } \\
\text { Material }\end{array}$ \\
\cline { 2 - 3 } & $\overline{\mathrm{x}}$ & $\mathrm{sD}$ & \\
\hline RTM & 1.227 & 0.042 & 0.536 \\
RTB & 1.091 & 0.052 & 0.587 \\
Particle size (mm) & & & \\
$0-1$ & 1.395 & 0.039 & 0.472 \\
$1-2$ & 0.952 & 0.032 & 0.640 \\
$2-4$ & 0.775 & 0.045 & 0.710 \\
$4-8$ & 0.708 & 0.058 & 0.732 \\
$>8$ & 0.692 & 0.071 & 0.738 \\
\hline
\end{tabular}

${ }^{2}$ The particle density of the tuff was determined to be $\overline{\mathbf{x}}=2.643$ $\mathrm{g} \cdot \mathrm{cm}^{-3}\left(\mathrm{SD}=0.021 \mathrm{~g} \cdot \mathrm{cm}^{-3}\right)$.

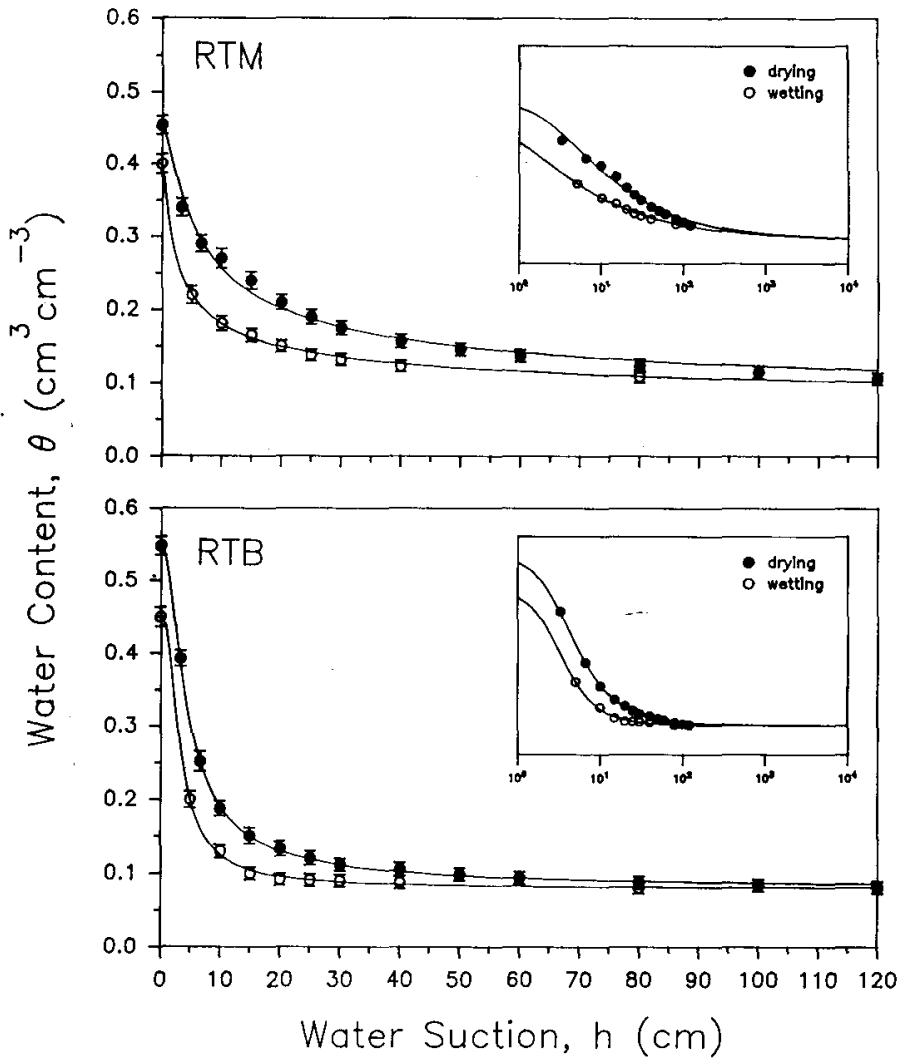

Fig. 3. Measured (symbols) and fitted (lines) main drying and primary wetting retention curves. Inserts represent the same as the main figure but with a logarithmic horizontal axis.

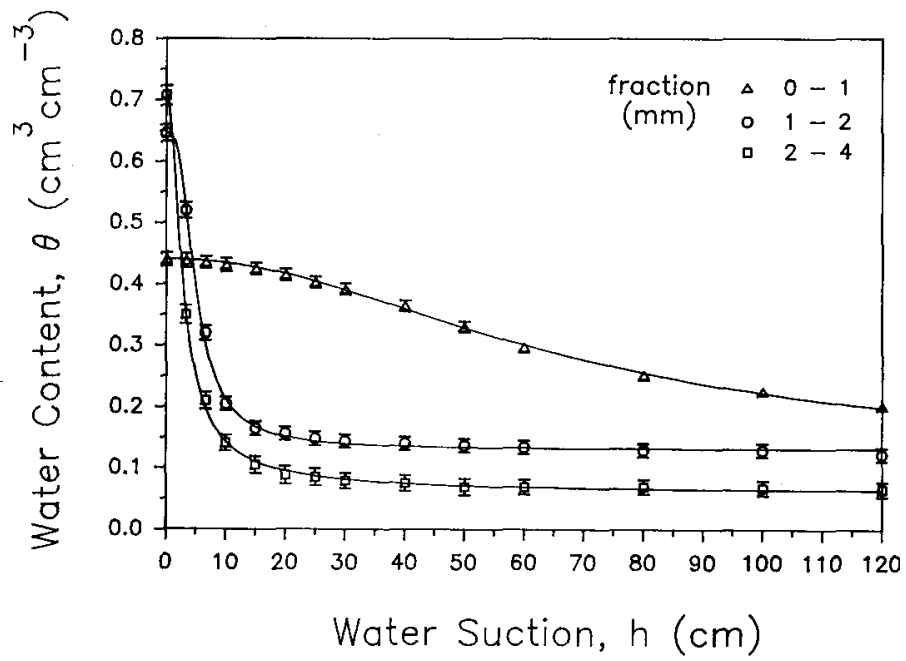

Fig. 4. Measured (symbols) and fitted (lines) main drying retention curves of a 1- to 2-mm fraction of red tuff and quartz sand.

by comparing the $\theta$ (h) curve of a 1- to 2-mm fraction of tuff with a similarly textured sand (Fig. 5).

The coarser tuff (RTB) seemed to be less affected by hysteresis than RTM, although in the 5- to $25-\mathrm{cm}$ suction range, significant differences in $\theta$ between the drying and wetting curves were easily detected for both materials (Fig. 3). Since irrigation practices involve successive cycles of wetting and drying, the water retention and flow are dominated by functions that are 


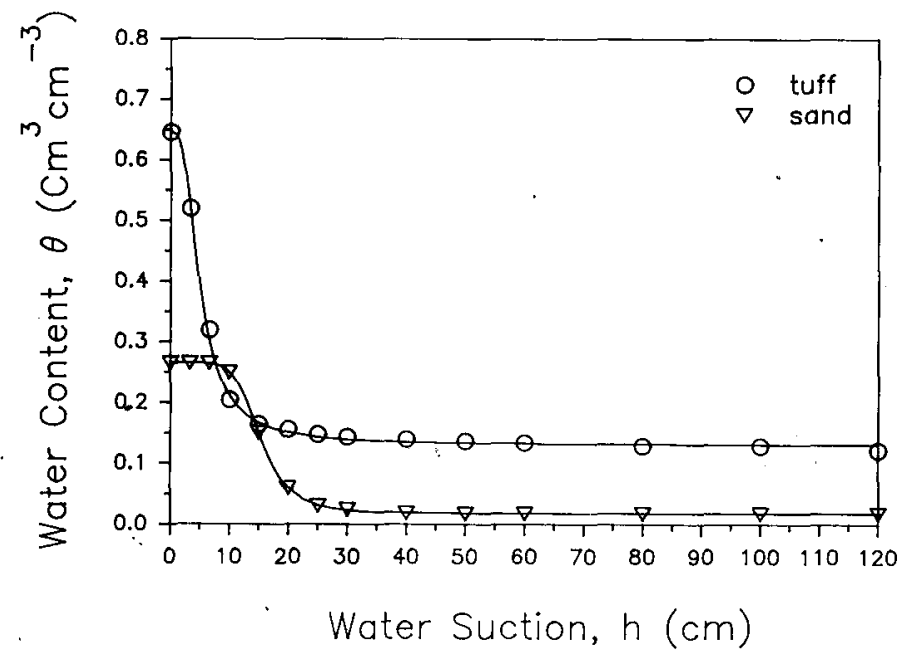

Fig. 5. Measured (symbols) and fitted (lines) main drying retention curve of various fractions of red tuff.

not uniquely defined [i.e., the $\theta(\mathrm{h})$ and $\mathrm{K}$ (h) functions, which depend on the history of wetting and drying]. Therefore, for each value of $h$, the corresponding value of $\theta$ can be anywhere within the covered hysteretic range.

Comparison of fitted curves with observed data gives some insight into model accuracy. In Fig. 3, the nonlinear least-squares fit of Eq. [2] is presented along with the observed data. The parameters $\alpha, \mathrm{n}$, and $\theta_{\mathrm{r}}$ are shown in Table 3 , along with the measured values of $\theta_{s}$, and $\theta_{w}$. For RTB, an excellent fit of both drying and wetting retention data was obtained throughout the whole suction range. For RTM (Fig. 3, top) a good fit of measured data was obtained, although the model seems to slightly deviate from some of the observed data at the higher water contents, while toward the dry end of the curve the prediction seems to be somewhat high. The wetting branch shows an excellent agreement between measured and fitted values. The ability of the model to predict the measured data in the vicinity of saturation and over the lower suction range is of particular importance for the prediction of $\mathrm{K}(\mathrm{h})$ and can be seen more clearly when a logarithmic scale is adopted for $\mathrm{h}$ (see inserts).

The experiment was reversed at $\mathrm{h}=120 \mathrm{~cm}$ rather than at $h\left(\theta_{r}\right)$, taking into consideration the fact that the range of $h=$ $\mathrm{O}$ to $120 \mathrm{~cm}$ easily covers the range of horticultural interest.
Since the value of $\theta_{r}$, estimated by the model from main drying retention data, was considered as a freed parameter for the estimation of the primary wetting curve, the two curves did not merge at $\mathrm{h}=120 \mathrm{~cm}$, although only small differences between the two were registered. Despite that assumption, the estimation of the wetting curves was very accurate for both materials.

Regression precision was evaluated using the coefficient of determination $\left(r^{2}\right)$ and the standard error coefficients (SE) (Table 3 ). Except for the drying branch for RTM, $r^{2}$ was very high in all cases (> 0.99), thus indicating that the model accurately fits the data. Fitted model curves for the different fractions of tuff also show an excellent agreement with measured data (Fig. 4), thus indicating that the model can be applied to retention data of media consisting of highly diverse particle size distribution and to the granular media with combined micro- and macropores. The ability of the model to accurately describe the retention data is an essential prerequisite for predicting unsaturated hydraulic conductivity (van Genuchten and Nielsen, 1985). It is expected, therefore, that a reliable $\mathrm{K}(\mathrm{h})$ relationship will be obtained for the media studied.

For both RTM and RTB, $\mathrm{K}_{\mathrm{s}}$ was determined at relatively lowgradients ( 0.5 and 0.2 , respectively). At higher gradients, deviations from Darcy's law were observed, and a quadratic rather than linear relationship between the flux and the gradient exists (Fig. 6). An additional advantage of measuring\& at low gradients is to avoid high flow rates. This is important since gradients as high as 6 were used in the determination of $\mathrm{K}_{\mathrm{s}}$ for similar media (Galin and Singer, 1988). The\& values for RTM and RTB, as well as for various fractions of tuff, are presented in Table 4.

For both materials, the predicted hydraulic conductivity decreased by more than three orders of magnitude over the O- to $25-\mathrm{cm}$ suction range and decreased further with increasing suction (Fig. 7). The hysteresis observed in $\theta$ (h) was reflected in $\mathrm{K}(\mathrm{h})$. On the wetting curve, $\mathrm{K}$ decreased about five orders of magnitude for RTM and more than six orders of magnitude for RTB between suctions of $\mathrm{O}$ and $25 \mathrm{~cm}$. This is a much greater decrease than was observed for the drying branch.

For the purpose of verifying the calculated $\mathrm{K}(\mathrm{h})$ relationship, we used the steady-state flux control method in drainage experiments, i.e., all infiltration experiments started at saturation and proceeded to lower fluxes, because much more time would be required to conduct wetting experiments (Yeh and Harvey, 1990).

For both RTB and RTM, measured $\mathrm{K}(\mathrm{h})$ values verified the calculated $\mathrm{K}(\mathrm{h})$ relationship over the 0 - to 25 -cm suction range

Table 3. Fitted values, standard errors (in parentheses), and coefficient of determination $\left(r^{2}\right)$ for the unknown parameters in Eq. [2] and measured values of $\theta_{s}$ and $\theta_{w}$ for RTM, RTB, and various fractions of the bulk tuff material.

\begin{tabular}{|c|c|c|c|c|c|c|c|c|c|c|}
\hline \multirow[b]{2}{*}{ Material } & \multirow[b]{2}{*}{ Curve $^{z}$} & \multicolumn{9}{|c|}{ Model parameters } \\
\hline & & $\mathrm{a}$ & & $\mathrm{n}$ & & $\theta_{\mathrm{r}}$ & & $r^{2}$ & $\theta_{\mathrm{s}}$ & $\theta_{\mathrm{w}}$ \\
\hline \multirow[t]{2}{*}{ RTM } & D & 0.346 & $(0.038)$ & 1.529 & $(0.030)$ & 0.063 & $(0.023)$ & 0.990 & 0.454 & \\
\hline & W & 1.000 & $(0.086)$ & 1.455 & $(0.014)$ & & & 0.999 & & 0.400 \\
\hline \multirow[t]{2}{*}{ RTM } & D & 0.324 & $(0.063)$ & 2.186 & $(0.034)$ & 0.079 & $(0.020)$ & 1.000 & 0.548 & \\
\hline & $\mathrm{W}$ & 0.387 & $(0.026)$ & 2.534 & $(0.080)$ & & & 0.999 & & 0.450 \\
\hline \multicolumn{11}{|c|}{$\begin{array}{l}\text { Particle } \\
\quad \text { size }(\mathrm{mm})\end{array}$} \\
\hline $0-1$ & $\mathrm{D}$ & 0.019 & $(0.000)$ & 2.195 & $(0.028)$ & 0.078 & $(0.000)$ & 1.000 & 0.440 & \\
\hline $1-2$ & $\mathrm{D}$ & 0.254 & $(0.040)$ & 3.022 & $(0.094)$ & 0.130 & $(0.020)$ & 0.999 & 0.646 & \\
\hline $2-4$ & $\mathrm{D}$ & 0.501 & $(0.187)$ & 2.263 & $(0.057)$ & 0.060 & $(0.020)$ & 0.999 & 0.710 & \\
\hline
\end{tabular}

${ }^{2} \mathrm{D}=$ main drying curve, $\mathrm{W}=$ primary scanning wetting curve. 

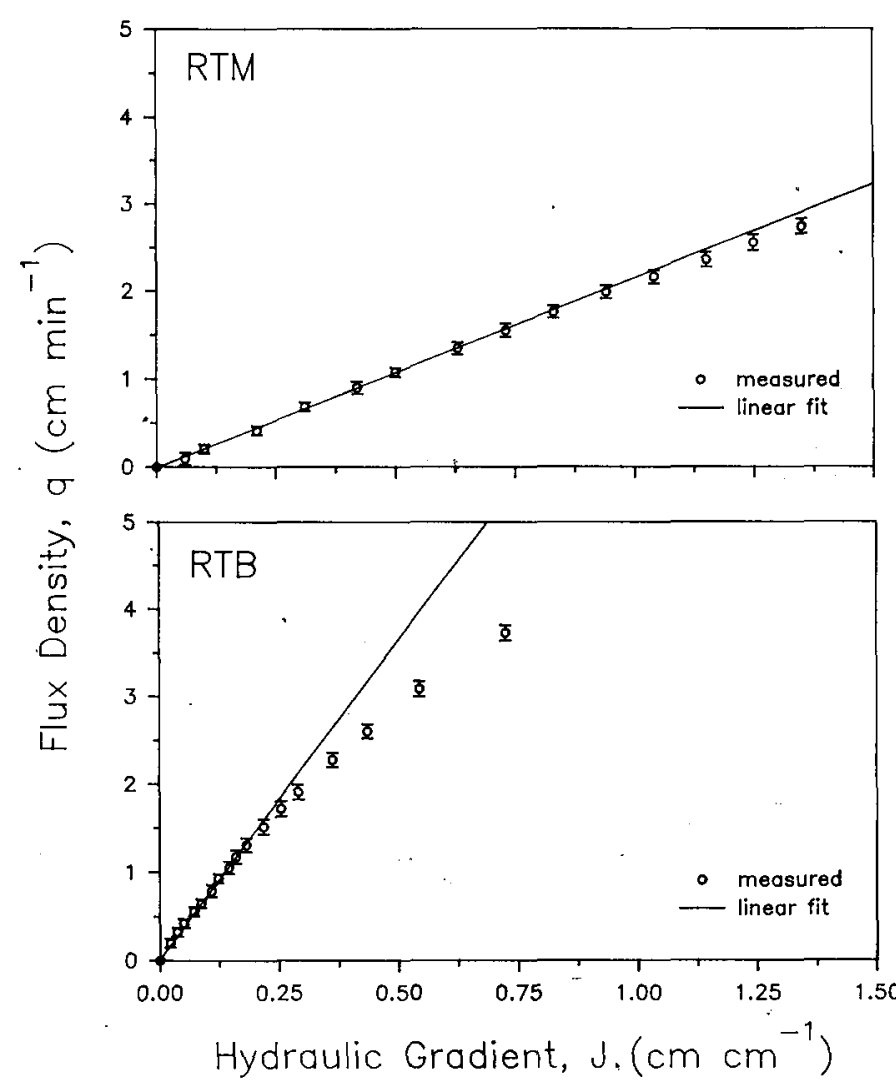

Fig.6. Flux density vs. hydraulic gradient. The linear range indicates the range of validity of Darcy's law over which the value of $\mathrm{K}_{\mathrm{s}}$ was determined.

Table 4. Mean $(\overline{\mathbf{x}})$ and standard deviation (SD) values of the saturated hydraulic conductivity $\mathrm{K}_{\mathrm{s}}$ and the corresponding hydraulic gradient J. for RTM, RTB, and for various fractions of the bulk tuff material.

\begin{tabular}{lccc}
\hline \hline & \multicolumn{2}{c}{$\begin{array}{c}\mathrm{K}_{\mathrm{s}} \\
\left(\mathrm{cm} \cdot \mathrm{min}^{-1}\right)\end{array}$} & $\begin{array}{c}\mathrm{J} \\
\text { Material }\end{array}$ \\
\cline { 2 - 3 } & $\overline{\mathbf{x}}$ & $\mathrm{SD}$ & $\left(\mathrm{cm} \cdot \mathrm{cm}^{-1}\right)$ \\
\hline RTM & 2.17 & 0.02 & 0.20 \\
RTB & 7.32 & 0.14 & 0.50 \\
Particle size (mm) & & & \\
0-1 & 0.46 & 0.02 & 3.0 \\
1-2 & 8.38 & 0.11 & 0.50 \\
2-4 & 10.39 & 0.15 & 0.20 \\
\hline
\end{tabular}

(Fig. 8). For the higher values of q, the agreement between measured and predicted values seems to be very high. As q was lowered, however, fluctuations in tensiometer readings were observed. These fluctuations could have resulted from the difficulty in establishing and controlling constant low fluxes with the equipment used. Very low fluxes $\left(<10^{-4} \mathrm{~cm} \cdot \mathrm{min}^{-1}\right)$ were required to achieve suctions of $\approx 20$ to $25 \mathrm{~cm}$, depending on the medium. However, these fluxes are much lower than those obtained using drippers or minisprinklers in the irrigation of container media. We therefore conclude that the steady-state flux control method is applicable to container media such as tuff, at least in the tested range of water suctions. For comparison between calculated steady-state suction profiles and measured data, three steady-state flow regimes were considered. The simulated profiles followed the experimental data accu-
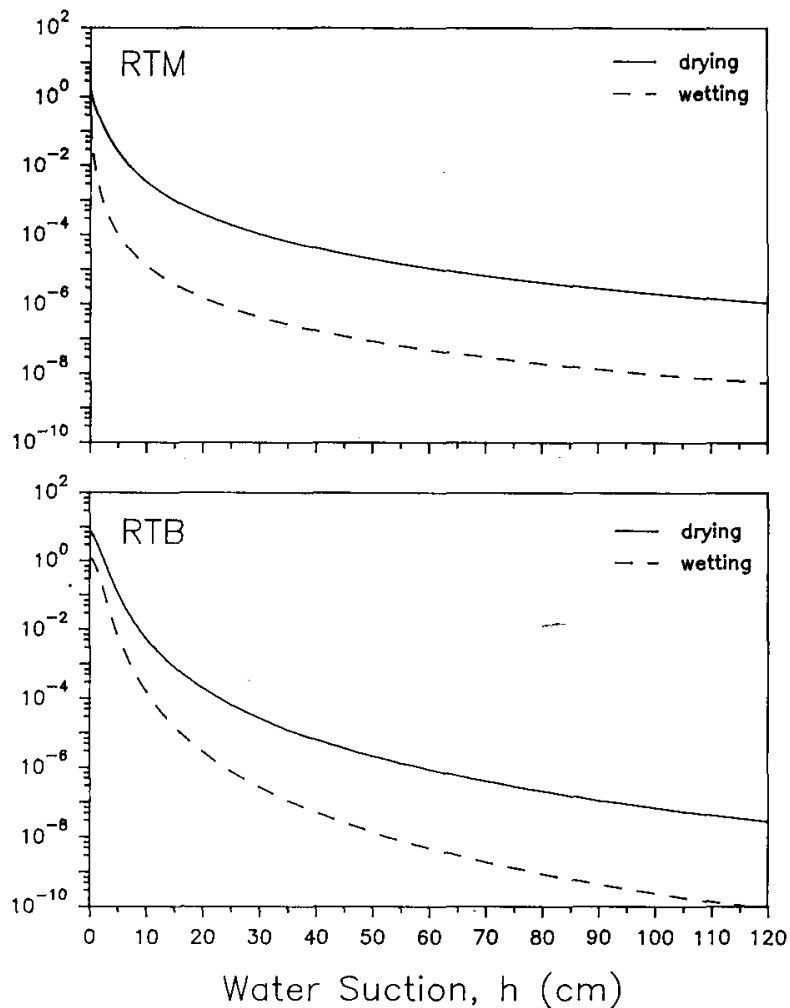

Fig. 7. Calculated hydraulic conductivity as a function of water suction. The drying and wetting hydraulic conductivity curves were calculated from the curve-fitted drying and wetting retention curves.
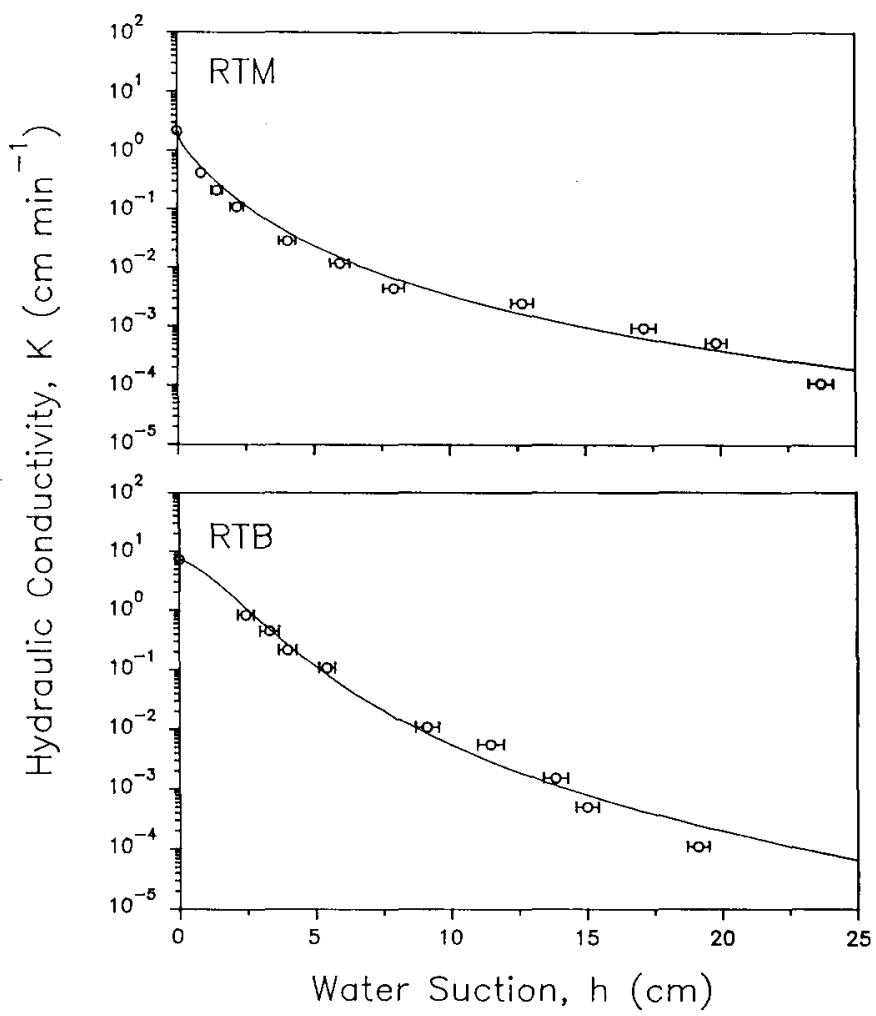

Fig. 8. Measured (symbols) and calculated (lines) main drying hydraulic conductivity as a function of water suction.

rately, considering the heterogeneous nature of the analyzed media (Fig. 9). Other measured suction distributions that were 


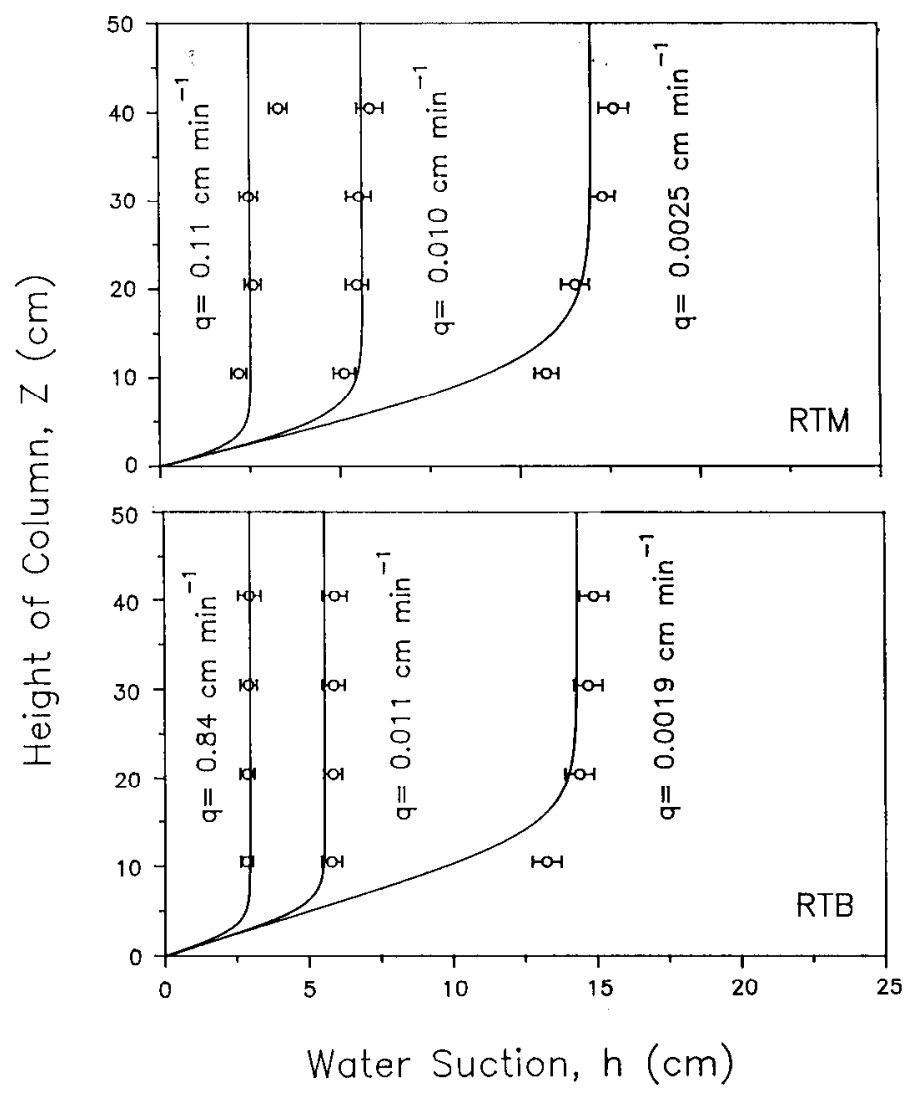

Fig. 9. Measured (symbols) and simulated (lines) suction profiles under three different regimes of steady-state downward flow.

obtained for fluxes in the range shown in Fig. 8 are not presented but gave similar fit to the simulated distributions.

The results obtained seem to support the use of an existing model that is frequently applied to soils for describing the hydraulic properties of granular coarse media, such as tuff. The nonlinear equation proposed by van Genuchten (1980) provides a useful tool for rescripting the water retention curves of soil substitutes, as demonstrated by Milks et al. (1989) and confirmed in this study. When this equation is combined with the unsaturated hydraulic conductivity model of Mualem (1976), a reliable prediction of the $\mathrm{K}(\mathrm{h})$ curve of these media is possible as well. The calculated $\mathrm{K}$ values were validated both by a direct and an indirect approach in the low suction range of $\mathrm{O}$ to 25 $\mathrm{cm}$. This is the suction range of horticultural concern, where most drastic changes in water-holding characteristics and in hydraulic conductivity of horticultural media take place. Since water availability to plants strongly depends on the hydraulic conductivity of the substrate used as growth medium, the wide variation of $\mathrm{K}(\mathrm{h})$ should not be overlooked. The functions of both $\theta(\mathrm{h})$ and $\mathrm{K}(\mathrm{h})$ can now be applied to transport models of water and chemicals for understanding the unsaturated water flow in container media. The challenge will be the optimization of irrigation in such media.

\section{Literature Cited}

Chen, Y., A. Banin, and Y. Ataman. 1980. Characterization of particles, pores, hydraulic properties and water-air ratios of artificial growth media and soil. Proc. Fifth Intl. Conf. Soilless Culture, Wageningen, The Netherlands. p.63-82.

Fonteno, W.C. and T.E. Bilderback. 1983. Physical property changes in three container media induced by a moisture extender. HortScience 18:570-574.

Fonteno, W.C., D.K. Cassel, and R.A. Larson. 1981. Physical properties of three container media and their effect on poinsettia growth. J. Amer. Soc. Hort. Sci. 106:736-741.

Galin, T. and A. Singer. 1988. Changes in tuff-lapilli from the Golan Heights resulting from their use as growth medium. Soilless Cult. 4:3-22.

Karlovich, P.T. and W.C. Fonteno. 1986. The effect of soil moisture tension and volume moisture on the growth of chrysanthemum in three container media. J. Amer. Soc. Hort. Sci. 111:191-195.

Klute, A. 1986. Water retention: Laboratory methods. In: Methods of soil analysis. Part 1. Physical and mineralogical methods. Agron. Monogr. 9. 2nd ed.

Klute, A. and C. Dirksen. 1986. Hydraulic conductivity and diffusivity: Laboratory methods, p. 687-734. In: A. Klute (cd.). Methods of soil analysis. Part 1. Physical and mineralogical methods. Amen. Monogr. 9. 2nd ed.

Luque, A. 1981. Physical and physico-chemical properties of volcanic materials used in hydropony. Acta Hort. 126:51-56.

Milks, R.R., W.C. Fonteno, and R. Larson. 1989. Hydrology of horticultural substrates: I. Mathematical models for moisture characteristics of horticultural container media. J. Amer. Soc. Hort. Sci. $144: 48-52$.

Mualem, Y. 1976. A new model for predicting the hydraulic conductivity of unsaturated porous media. Water Resources Res. 12:513522.

Mualem, Y. 1986. Hydraulic conductivity of unsaturated soils, p. 799823. In: A. Klute (ed.). Methods of soil analysis. Part 1. Physical and mineralogical methods. Agron. Monogr. 9. 2nd ed.

Unver, I., Y. Ataman, and N. Munsuz. 1983. Water retention characteristics for some substrates used in Turkey. Acta Hort. 150:161168.

van Genuchten, M.T. 1978. Calculating the unsaturated hydraulic conductivity with a new closed-form analytical model. Dept. of Civil Eng., Princeton Univ., New Jersey, Res. Rpt. 78-WR-08.

van Genuchten, M.T. 1980. A closed-form equation for predicting the hydraulic conductivity of unsaturated soils. Soil Sci. Soc. Amer. J. 49:12-19.

van Genuchten, M.T. and D.R. Nielsen. 1985. On describing and predicting the hydraulic properties of unsaturated soils. Annales Geophysical 3:615-628.

Yeh, T.C.J. and D.J. Harvey. 1990. Effective unsaturated hydraulic conductivity of layered sands. Water Resources Res. 26:12711279.

Yeh, T.C.J. 1989. One-dimensional steady-state infiltration in heterogeneous soils. Water Resources Res. 25:2149-2158. 